\title{
Constipation and functional faecal retention in a group of school children in a district in Sri Lanka
}

\author{
Shaman Rajindrajith ${ }^{1}$, Niranga Manjuri Devanarayana ${ }^{2}$, Sachith Mettananda ${ }^{3}$, Priyantha Perera ${ }^{1}$, \\ Sanofer Jasmin ${ }^{4}$, Udara Karunarathna ${ }^{4}$, Deshan Adhihetty ${ }^{5}$, Ruwan Goonewardena ${ }^{5}$
}

Sri Lanka Journal of Child Health, 2009; 38: 60-64

(Key words: constipation, functional faecal retention, Rome III criteria, children, adolescents)

\begin{abstract}
Objective To assess the prevalence of constipation and functional faecal retention among a group of school children in Gampaha district of Sri Lanka.

Method This is a cross sectional survey. A validated, self-administered questionnaire was distributed to randomly selected children, aged 1016 years, in a semi-urban school in Gampaha District of Sri Lanka. Constipation was defined using Rome III criteria and Paris Consensus on Childhood Constipation Terminology (PACCT). Functional faecal retention was diagnosed using Rome II criteria.
\end{abstract}

Results A total of 441 questionnaires were distributed and $429(97.3 \%)$ responded (53.1\% males, mean age 12.4 years, SD 1.5 years). According to Rome III criteria and PACCT, 46 $(10.7 \%)$ had constipation. Prevalence of constipation was higher in males $(14.5 \%)$ compared to females $(6.5 \%)$ [OR $2.45,95 \%$ CI 1.19-5.1, $\mathrm{p}=0.012]$. Twenty three $(5.4 \%)$ had functional faecal retention.

Conclusions Chronic constipation is a significant problem, affecting approximately $10 \%$ of children in a semi-urban school in Gampaha district. It is commoner among males. Both Rome III criteria and PACCT are effective in diagnosing childhood constipation in epidemiological studies.

\section{Introduction}

Constipation is a global health problem, affecting children and adolescents, which has a great impact on quality of life of both affected children and parents. The prevalence of constipation varies from 0.7 in Italy to 29.6 in Hong Kong ${ }^{1}$. It accounts for approximately $3 \%$ of visits to general paediatric

\footnotetext{
${ }^{1}$ Senior lecturer in Paediatrics, ${ }^{2}$ Senior Lecturer in Physiology, ${ }^{3}$ Lecturer in Paediatrics, ${ }^{4}$ Demonstrator in Physiology, ${ }^{5}$ Demonstrator in Paediatrics, Faculty of Medicine, University of Kelaniya
}

(Received on 23 July 2008. Accepted after revision on 27 February 2009) clinics $^{2}$ and $25 \%$ visits to gastroenterology clinics ${ }^{3}$. Up to date, there is no data on the prevalence of this important clinical problem among Sri Lankan children. It has been widely studied in the west, but to date there is a scarcity of epidemiological data from the developing word. This has led to the false belief that it is a disease of the western world.

Due to lack of a uniform definition, diagnosing constipation had been an extremely difficult task in clinical and epidemiological studies. To overcome this problem, Rome II group have defined criteria for diagnosing constipation and functional faecal retention. These criteria define constipation only in infants and toddlers and functional faecal retention is diagnosed only in older children ${ }^{4}$. In subsequent studies, these criteria were shown to be too restrictive in diagnosing defaecation disorders in children $^{5,6}$ and therefore, the Paris Consensus for Childhood Constipation Terminology (PACCT) group introduced a new definition in $2005^{7}$. In 2006, Rome II criteria were revised and the new Rome III criteria for paediatric constipation were introduced $^{8}$.

The objectives of this study were to study the prevalence of constipation and functional faecal retention among a group of school children from Gampaha district and clinical features associated with them.

\section{Method}

This is a cross sectional survey carried out in a semi-urban school in Gampaha district of Sri Lanka. Five classes were randomly selected from the academic years 6 to 10 and all students (10-16 years) in the selected classes were included in study. A validated, self administered questionnaire was distributed and was filled under the guidance of research assistants. Details of bowel habits during the previous 3 months were collected along with information on demographic features and family history of constipation. The presence of associated symptoms (e.g. abdominal pain, nausea, vomiting etc.) were also noted. 
Constipation was defined using Rome III criteria ${ }^{8}$ (Table 1) and the Paris Consensus of Childhood Constipation Terminology (PACCT) group guidelines $^{7}$ (Table 1). Functional faecal retention was defined using Rome II criteria ${ }^{4}$ (Table 2). Consistency of stool was determined using Bristol stool chart ${ }^{9}$.

Table 1

Diagnostic criteria for childhood constipation

\begin{tabular}{|c|c|}
\hline Rom & term \\
\hline $\begin{array}{l}\text { - } 2 \text { or fewer defaecations per week } \\
\text { - } \text { At least } 1 \text { episode of faecal incontinence per } \\
\text { week } \\
\text { - } \quad \text { Retentive posturing or excessive volitional } \\
\text { stool retention } \\
\text { - } \quad \begin{array}{l}\text { Presence of large faecal mass in the rectum } \\
\text { - }\end{array} \text { History of large diameter stools that may } \\
\text { obstruct the toilet } \\
\text { - Painful or hard bowel motions }\end{array}$ & $\begin{array}{l}\text { east } 2 \text { of the following criteria fulfilled for at least } \\
\text { onths } \\
\text { - Frequency of bowel movements }<3 \text { per week } \\
\text { - More than one episode of faecal incontinence } \\
\text { per week } \\
\text { - Retentive posturing and withholding } \\
\text { behaviour } \\
\text { - Large stool in the rectum or palpable on } \\
\text { abdominal examination } \\
\text { - Passing stools so large that they may obstruct } \\
\text { the toilet } \\
\text { - Painful defaecation }\end{array}$ \\
\hline
\end{tabular}

\section{Results}

Table 2

Rome II diagnostic criteria for functional faecal retention

From infancy to 16 years old, a history of at least 12 weeks of

- Passage of large diameter stool at intervals $<2$ times per week and

- Retentive posturing, avoiding by purposefully contracting the pelvic floor. As pelvic floor muscles fatigue the child uses the gluteal muscles, squeezing the buttocks together

Data was analysed using Fisher exact test and $\chi 2$ test [EpiInfo 6, version 6.04 (1996), Centres of Disease Control and Prevention, Atlanta, Georgia, USA and World Health Organization, Geneva, Switzerland]. $\mathrm{P}<0.05$ was considered significant.

This study was approved by the Ethical Review Committee of the Sri Lanka College of Paediatricians.
A total of 441 questionnaires were distributed and $429(97.3 \%)$ responders were included in final analysis (males 53.1\%). Ages ranged from 10-16 years with a mean age of 12.4 years (SD 1.5 years) [males 12.4 years (SD 1.51 years) and females 12.4 years (SD 1.52 years)].

Prevalence of constipation and functional faecal retention

According to Rome III and PACCT criteria, 46 $(10.7 \%)$ had constipation (Table 3$)$. The mean age of children with constipation was 10.6 years (SD 2.6 years) [males 12.01 years (SD 1.53 years), females 12.5 years (SD 1.63 years)]. Constipation was more common in males $(p=0.01)$. The distribution of children with constipation according to age groups and sex is shown in the Figure 1.

During analysis, the 46 children who fulfilled the criteria for constipation were compared with 375 healthy children without defaecation disorders (controls). According to Rome II criteria 23 (5.4\%) had functional faecal retention [mean age 12.1 years, SD 1.72] (Table 3).

Clinical features associated with constipation Factors associated with constipation are presented in Table 4. Constipation was significantly higher in those with a family history of constipation. 


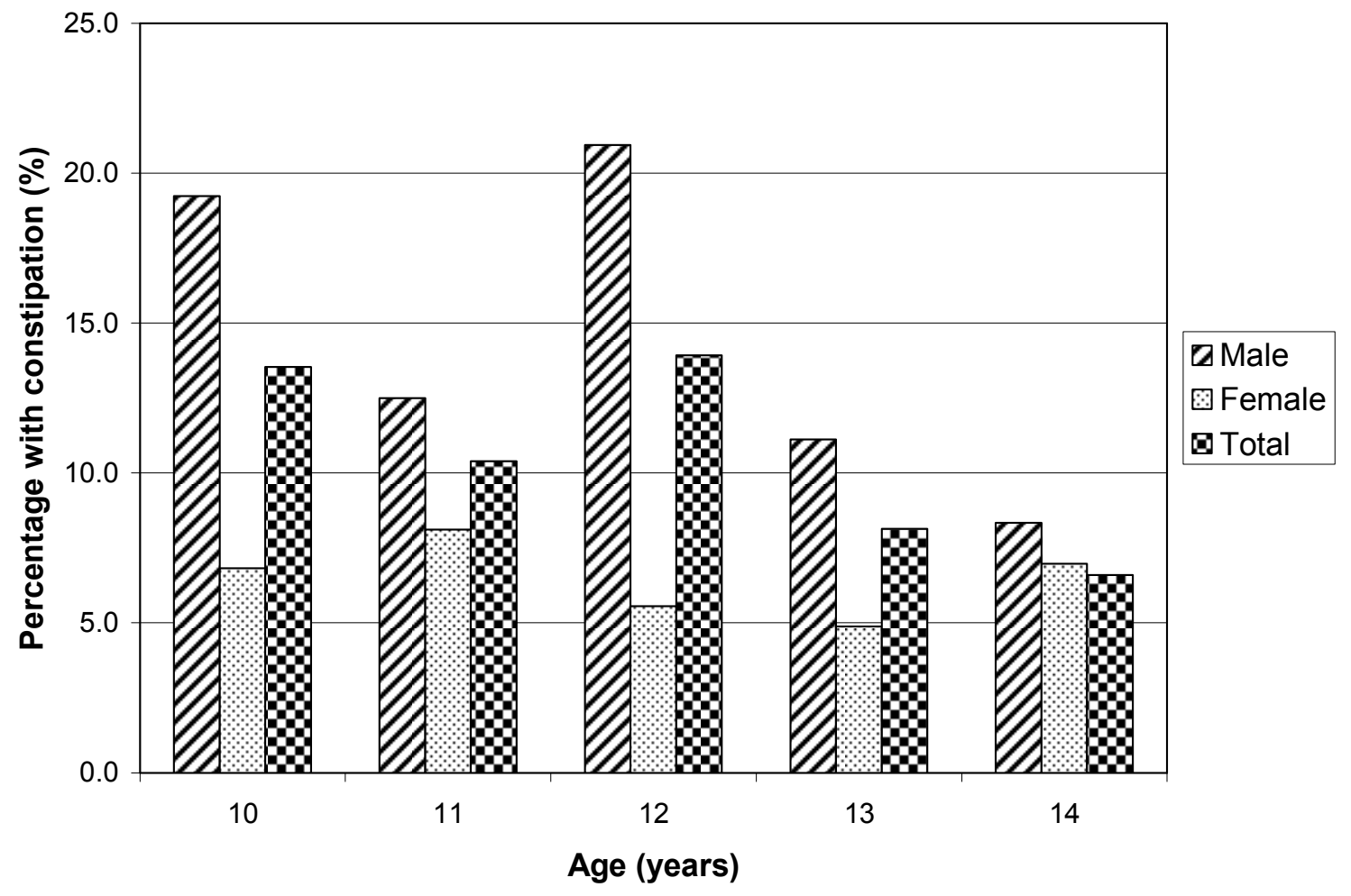

Figure 1 - Distribution of children with constipation according to age and sex

Table 3

Prevalence of constipation and functional faecal retention according to $\operatorname{sex}(n=429)$

\begin{tabular}{|l|l|c|c|}
\hline \multicolumn{1}{|c|}{ Diagnosis } & Male n=227 & Female n=202 & Total n=429 \\
\hline Constipation according to Rome III criteria & $33(14.5 \%)^{*}$ & $13(6,5 \%)$ & $46(10.7 \%)$ \\
\hline Constipation according to PACCT & $33(14.5 \%)^{*}$ & $13(6,5 \%)$ & $46(10.7 \%)$ \\
\hline $\begin{array}{l}\text { Functional faecal retention according to Rome II } \\
\text { criteria }\end{array}$ & $13(05.7 \%)$ & $10(4.8 \%)$ & $23(05.4 \%)$ \\
\hline
\end{tabular}

*OR $=2.45$ (95\% CI 1.19-5.1), $\mathrm{p}=0.012$, Chi-square test

Table 4

Clinical features associated with constipation

\begin{tabular}{|l|c|c|c|}
\hline & Constipation group (n=46) & Control group (n=375) & p value* \\
\hline Presence of straining & $34(73.9 \%)$ & $121(32.3 \%)$ & $<0.00001$ \\
\hline Bleeding per rectum & $09(19.6 \%)$ & $16(4.3 \%)$ & 0.0001 \\
\hline Abdominal pain & $26(56.5 \%)$ & $175(46.7 \%)$ & 0.26 \\
\hline Nausea & $06(13.0 \%)$ & $28(7.5 \%)$ & 0.3 \\
\hline Vomiting & $10(21.7 \%)$ & $20(5.3 \%)$ & 0.0001 \\
\hline Anorexia & $06(13.0 \%)$ & $48(12.8 \%)$ & 0.8 \\
\hline Weight loss & $13(28.3 \%)$ & $45(12 \%)$ & 0.005 \\
\hline Perianal wounds/ulcerations & $10(21.7 \%)$ & $07(1.9 \%)$ & $<0.00001$ \\
\hline Family history of constipation & $07(15.2 \%)$ & $11(2.9 \%)$ & 0.0005 \\
\hline
\end{tabular}

*Chi-square test 


\section{Discussion}

Prevalence of constipation and functional faecal retention in our study sample of school children aged 10-16 years were $10.7 \%$ and $5.4 \%$ respectively. Constipation was more common in males, and those with a positive family history. Vomiting, weight loss, straining, bleeding per rectum, and perianal fissures were more common in the affected children.

Considering the high prevalence of constipation, its impact on lives of patients, parents and family members, and its burden on health care system, little was known of its epidemiology in developing countries including Sri Lanka. Prevalence of constipation varies around the world. In agreement with our results, Uguralp et al. have reported constipation in $12.4 \%$ of Turkish school children in Malatya district ${ }^{10}$. Studying preschool children from Eastern district of Hong Kong, Ip et al found $29.6 \%$ of them having constipation ${ }^{11}$. In Rio de Janeiro, Brazil $28 \%$ of school children were noted to be having constipation ${ }^{12}$. However, in contrast to common belief, lower prevalence of constipation has been reported in some western studies. In USA a single clinic based study reported constipation in $3.2 \%$ of children ${ }^{13}$.

The differences in the prevalence of constipation in various studies cited above are due to several factors, but mainly due to the variations of definitions used by the researchers. For example de Arajuo Sant' Ann and Calcado had defined constipation as difficulty during defaecation often or sometimes ${ }^{12}$ which may be found in children without constipation. Ip et al. used Rome II criteria $^{11}$. However, given the restrictive nature of the Rome II criteria in diagnosing defaecation disorders, the prevalence is very high in Hong Kong. Furthermore, low prevalence found by Leoning-Boucke may also be due to the selection of the sample from the children attending to a general paediatric clinic $^{13}$. Finally the differences in the prevalence rates may be due to cultural, racial environmental and socio-economic conditions. Therefore, more robust definition and better sampling frames are necessary to identify the precise epidemiology of this important public health problem.

To date, only one community based study has assessed prevalence of functional faecal retention. Functional faecal retention is only defined in Rome II criteria and therefore studies before 1999 do not recognize it. Uc et al. studied 243 African American children attending to a single community clinic found only $1(0.4 \%)$ child with this condition $^{14}$. We found functional faecal retention in a higher percentage of children (5.4\%). Inadequate toilet facilities in schools, which are frequently unhygienic, often lead to stool withholding and therefore functional faecal retention.

Prevalence of constipation was significantly higher in males in our study. Contrary to this, two studies from Asia reported higher prevalence of constipation among females ${ }^{11}$. Several other studies found no sex difference in this condition ${ }^{10,15,16}$. We did not find a significant difference in prevalence of functional faecal retention in males and females. Sex difference of functional faecal retention has not been studied in the world.

Even though straining is not a diagnostic criterion for constipation, it was seen in approximately $75 \%$ of Sri Lankan children with constipation. This is higher than reported in previous studies $(35 \%)^{17}$. Therefore, we feel that straining should be included as a diagnostic criterion for childhood constipation. Abdominal pain and distension, anorexia, vomiting, blood streaked stools and urinary tract infection and enuresis are common symptoms associated with constipation ${ }^{12,17,18}$. Similar to previous studies, bleeding per rectum, vomiting, weight loss and perianal fissures were more common in the affected children in our study.

We found a significant association between constipation and the presence of similar disease among first degree relatives, a finding reported previously ${ }^{11,19}$. Furthermore, the concordance for constipation was reported to be six times greater among identical twins than among fraternal twins ${ }^{20}$. The genetic and environmental vulnerability of constipation needs further clarification to identify a definite genetic predisposition.

In conclusion, constipation is seen approximately $10 \%$ of school children aged 10-16 years in our study sample. Functional faecal retention is seen in nearly half of them. An island-wide survey is urgently needed to assess the prevalence, risk factors and associated features of constipation in Sri Lanka. Availability Rome III and PACCT criteria provide a firm platform for diagnosing paediatric defaecation disorders. This will facilitate studies on paediatric constipation and will generate more applicable epidemiological data worldwide.

\section{References}

1. van den Berg MM, Benninga MA, Di Lorenzo C. Epidemiology of childhood constipation: a systematic review. Am J Gastroenterol 2006; 101: 2401-9.

2. Levine MD. Children with encopresis: a descriptive analysis. Pediatrics 1975: 56: 412-6. 
3. Taitz LS, Water JKH, Urwin OM, Molner D. Factors associated with outcome in management of defecation disorders. Arch Dis Child 1986; 61: 472-7.

4. Rasquin-Weber A, Hymes PE, Cucchiara S, Fleisher DR, Hyans JS, Milla PJ, et al. Childhood functional gastrointestinal disorders. Gut 1999; 45 Suppl 2: II 60-8.

5. Loening-Baucke V. Functional fecal retention with encopresis in childhood. $J$ Pediatr Gastroenterol Nutr 2004; 38:79-84.

6. Voskuijl WP, Heijmans J, Heimans HAS, Taminiau JAJM, Benninga MA. Use of Rome II criteria in childhood defecation disorders: applicability in clinical and research practice. $J$ Pediatr 2004; 145:213-7.

7. Benninga MA, Candy DA, Catto-Smith AG, Clayden G, Loening-Baucke V, Di Lorenzo C, et al. The Paris consensus on childhood constipation terminology (PACCT) group. $J$ Pediatr Gastroenterol Nutr 2005; 40:273-5.

8. Rasquin A, Di Lorenzo C, Forber D, Guiraldes E, Hyams JS, Staiano A, et al. Childhood functional gastrointestinal disorders: child / adolescent. Gastroenterology 2006; 130:1527-37.

9. Lewis SJ, Heatoh KW. Stool form scale as a useful guide to intestinal transit time. Scand $J$ Gastroenterol 1997; 32:920-4.

10. Ugurlap S, Karaoglu L, Karaman A, Demircan M, Yakinci C. Frequency of enuresis, constipation and enuresis associated with constipation in a group of school children aged 5 9 years in Malatya, Turkey. Turk J Med Sci 2003; 33:315-20.

11. Ip KS, Lee WT, Chan JS, Young BYW. A community-based study of the prevalence of constipation in young children and the role of dietary fibre. Hong Kong Med J 2005; 11:431-6.
12. de Araujo Sant'Anna AM, Calcado AC. Constipation in school-aged children at public schools in Rio de Janeiro, Brazil. J Pediatr Gastroenterol Nutr 1999; 29:190-3.

13. Kajiwara M, Inoue K, Usui A, Kurihara M, Usui $\mathrm{T}$. The micturition habits and prevalence of day time urinary incontinence in Japanese primary school children. J Urol 2004; 171:403-7.

14. Uc A, Hyman PE, Walker LS. Functional gastrointestinal disorders in African American children in primary care. $J$ Pediatr Gastroenterol Nutr 2006; 42:27-74.

15. Iacono G, Merolla R, D'Amico D, Bonci E, Cavataio F, Di Prima L et al. Gastrointestinal symptoms in infancy: a population-based prospective study. Dig Liver Dis 2005; 37:432-8.

16. Roma-Giannikou E, Adamidis D, Gianniou M, Nikolara R, Messaritakis A. Epidemiology of chronic constipation in Greek children. Hell $J$ Gastroenterol 1999; 12:58-62.

17. Benninga MA, Voskuijl WP, Taminiau JAJM Childhood constipation: is there new light in the tunnel? J Pediatr Gastroenterol Nutr 2004; 39:448-64.

18. Croffie JM, Fitzgerald J. Idiopathic constipation In: Walker WA, Goulet O, Kleinman RE Sherman PM, Shneider BL, Sanderson IR, editors. Pediatric gastrointestinal disease. Ontario: BC Decker; 2004. p. 1000-15.

19. Roma E, Adamidis Nikolara R, Constantopoulos A, Messaritakis J. Diet and chronic constipation in children: the role of fibre. $J$ Pediatr Gastroenterol Nutr 1999; 28:169-74.

20. Backwin H, Davidson M. Constipation in twins. Am J Dis Child 1971; 121:179-81. 